\title{
BMJ Open Drivers of healthy eating in a workplace in Nepal: a qualitative study
}

\author{
Dipesh Tamrakar, ${ }^{1}$ Archana Shrestha (D) , ${ }^{2,3}$ Anjana Rai, ${ }^{4}$ Biraj Man Karmacharya, ${ }^{2}$ \\ Vasanti Malik, ${ }^{5}$ Josiemer Mattei, ${ }^{6}$ Donna Spiegelman ${ }^{7,8}$
}

To cite: Tamrakar D, Shrestha A Rai $A$, et al. Drivers of healthy eating in a workplace in Nepal: a qualitative study. BMJ Open 2020;10:e031404. doi:10.1136/ bmjopen-2019-031404

- Prepublication history for this paper is available online. To view these files, please visit the journal online (http://dx.doi. org/10.1136/bmjopen-2019031404).

Received 21 May 2019

Revised 03 February 2020

Accepted 05 February 2020
Check for updates

(C) Author(s) (or their employer(s)) 2020. Re-use permitted under CC BY-NC. No commercial re-use. See rights and permissions. Published by BMJ.

For numbered affiliations see end of article.

Correspondence to Dr Archana Shrestha; archana@kusms.edu.np

\section{ABSTRACT}

Objective To explore the perceptions, enablers and barriers to employees' healthy eating in a hospital site. Design A qualitative study including focus group discussion and in-depth interview, data were analysed using thematic analysis method.

Setting The study was carried out among employees of Dhulikhel Hospital-Kathmandu University Hospital, located about $30 \mathrm{~km}$ east of Nepal's capital Kathmandu.

Participants Focus group discussions were conducted among the 33 participants, who were divided into four groups: (a) support staff (drivers, cook, laundry, gardeners and ward boys), (b) hospital administrators and managers, (c) health personnel (doctors, nurses and assistants) who work 8-12 hours shifts and (d) health personnel who work during office hours. Nine in-depth interviews were conducted among six canteen operators and three managers.

Results The major factors for promoting healthy eating were identified as the availability of affordable healthy food options in the cafeterias, a commitment to such promotion by the cafeteria manager, operators, staff and hospital administration and the level of education of the employees. The most commonly reported barriers for healthy eating were the unavailability of healthy options, including the lack of food supply from local market, the higher cost of healthy foods, individual food preferences and limited human resources in the cafeteria.

Conclusion The availability of affordable healthy foods, supply of healthy foods from the market, commitment from cafeteria managers, hospital administrators and health awareness among cafeteria operators may promote healthy eating among employees in a Nepali hospital setting.

\section{INTRODUCTION}

Unhealthy eating is related to increased risk of chronic diseases, including heart disease, diabetes and cancer. ${ }^{1}$ Diet directly increases the risk of these chronic diseases, and also contributes to increased risk indirectly through overweight and obesity caused by poor diet. ${ }^{2}$ Diets high in whole grains, fruits and vegetables and low in red meat, saturated and trans-fat are recommended to reduce chronic disease. ${ }^{34}$

Eating behaviour results from a complex interplay of influences at the individual, social and environmental levels. Previous
Strengths and limitations of this study

This is first study to explore the facilitators and barriers for healthy eating in a Nepali hospital setting.

- The study represents the in-depth views of both cafeteria operators as well as cafeteria users from different strata of Nepali society, representing varied levels of income, professional status, education and work hours.

- There may have been social desirability bias during focus group discussions that affected how participants expressed their thoughts on healthy eating behaviours.

- The findings may not be generalisable to worksites other than a hospital setting.

- This study was primarily conducted to understand healthy eating and its determinants in a specific worksite setting and to develop interventions to promote healthy foods. It has not explored the broader environmental, contextual, social and commercial determinants of healthy eating.

studies have emphasised the importance of understanding enablers and barriers to healthy eating, including the presentation and composition of meals, access to healthy options, food price and other socio-cultural factors such as time management, family support and the social food environment. ${ }^{5-7}$ However, most of these findings are reported from high-income countries, not low/middleincome countries like Nepal.

Nepal is one of the least developed countries in the world. Nonetheless, due to rapid changes from an agricultural to a more urbanised work and lifestyle, including the advent of more processed foods, the country is experiencing an epidemiological transition from infectious to chronic diseases. In fact, ischaemic heart disease, chronic obstructive pulmonary disease and stroke were the top three causes of death in $2017 .^{8}$ One quarter of the adult Nepali population is overweight, $4 \%$ have diabetes and 26\% have hypertension. ${ }^{9}$ An unhealthy diet might have contributed to the high prevalence of these diseases and risk factors. ${ }^{10} 11$ In Nepal, the typical 
dietary pattern of refined grains, meat and alcohol is associated with a higher prevalence of overweight and obesity. ${ }^{10}$ Deep-fried foods are associated with hypertension; the cereal and vegetable pattern is inversely associated with diabetes prevalence. ${ }^{12}$

In light of this significant epidemiological transition, it is important to identify the social environments, including at the workplace, that influence healthy eating and consequent health outcomes. Given the considerable time employees spend on their jobs, worksites are an important venue and opportunity to reach large numbers of adults to facilitate healthy eating. ${ }^{13}$ In addition, workplaces might support long-term behavioural changes through social support and changes in available foods. ${ }^{1415}$ The efficacy of workplace approaches in promoting a healthy diet has been consistently reported in the literature. ${ }^{16}$ Workplaces can provide employees with the opportunities, resources and support that influence eating behaviour. ${ }^{17}$ The workplace food environment, especially food availability, preparation and price, can facilitate or create a barrier to healthy eating. ${ }^{1315}$

The literature assessing employees' opinions on healthy eating in the workplace is limited. ${ }^{18}$ Previous studies showed that workers are aware of the importance of changing unhealthy behaviours and that they are willing to eat healthy foods provided they are tasty, convenient, reasonably priced and of good quality. ${ }^{19}$ Previously reported barriers to healthy eating include long working hours, the unavailability of healthy food and the distance to and poor quality of dining facilities. ${ }^{6} 1820$

A study conducted in a factory in eastern Nepal reported that the availability of healthy foods at affordable prices, combined with an increased level of awareness and commitment from worksite management can result in healthier food choices in the workplace. ${ }^{21}$ Given that each workplace is a unique and complex environment, the present qualitative study aims to explore the perceptions and views of staff on healthy eating as well as the enablers and barriers to healthy eating at a hospital worksite in central Nepal.

\section{METHODS}

We conducted an exploratory qualitative study to investigate the perceptions, enablers and barriers to employees' healthy eating in a hospital. A qualitative design was chosen for the study because it aims to investigate the 'how' and 'why' of individual behaviour and is best suited to answering complex questions about food-related perceptions and behaviours. ${ }^{22}$

\section{Study site and settings}

This study was conducted at Dhulikhel HospitalKathmandu University Hospital (DH-KUH), an independent, not for profit, non-government, tertiary care institution that has 1040 employees, 400 beds and annually serves about 2.2 million people from within its catchment area, making it one of the largest tertiary level hospitals in central Nepal. The 1040 employees are of quite varied backgrounds, ranging from professional health personnel (doctors, nurses and assistants) and professional administrative staff to support staff (drivers, cook, laundry, gardeners and ward boys). DH-KUH has four cafeterias on the hospital premises that operate 16 hours a day. All four cafeterias are supervised by one manager and operated on a subsidised on or near a breakeven basis by DH-KUH. All four cafeterias serve breakfast, lunch and snacks and one also serves dinner.

The researchers from Nepal (DT, AS, BMK) are themselves all employees of DH-KUH and regular customers of the cafeteria. Each day, a pre-determined menu is offered for breakfast that includes kheer (milk and rice porridge), samosas (deep-fried vegetable dumplings made with wheat flour), puri (deep-fried wheat bread), vegetable curry, eggs, white bread and bakery items such as cakes, donuts, white buns and unsweetened, savoury puff pastries. Lunch usually consists of white rice, lentil soup, vegetable curry, chicken curry and yoghurt. Snacks include noodles, fried rice, biscuits, confectioneries and so on. Hot (tea, coffee) and cold beverages (sodas and soft drinks) are also available.

\section{Recruitment}

All employees of the hospital were eligible to participate in the present study. To represent the different staff cadre, we purposely grouped them into four distinct categories: (a) support staff, (b) administrators and managers, (c) health personnel who work 8-hour shifts throughout the day and night, and (d) health personnel who work during regular, daytime office hours. The decision to separate the health personnel into two groups, that is, those who work regular office hours and those working on 8-hour shifts throughout the day was taken because the availability of foods and working conditions differ for these two groups. A research assistant met potential participants in each group at a pre-scheduled time to explain the purpose of the study and administered an informed consent procedure to each participant, using a standard script until our required sample size was met. A total of 64 participants were approached for the four pre-determined focus group discussions (FGDs) and 40 agreed to participate. Seven of those who initially agreed to participate did not show up. In addition, we selected a finance manager, a cafeteria manager, an administrative manager and six cafeteria operators for in-depth interviews.

\section{Focus group discussions}

FGDs were conducted and audio taped in the Nepali language within the workplace setting, but in a private room to ensure confidentiality and honest sharing of opinions. Investigators AS or DT, moderated all FGDs, assisted by a note-taker. In each session, the moderator briefly introduced the study and explained the ethical considerations and procedures for maintaining confidentiality of the participants. The moderator asked open-ended questions and probed for more detailed information. We 
Table 1 Examples of the open-ended questions in each domain

\begin{tabular}{ll}
\hline Domain & Example questions \\
\hline $\begin{array}{l}\text { Perception of healthy and } \\
\text { unhealthy eating }\end{array}$ & $\begin{array}{l}\text { 'What do you understand by } \\
\text { 'What do you understand by } \\
\text { unhealthy foods?' }\end{array}$ \\
$\begin{array}{l}\text { Facilitators to healthy } \\
\text { eating at workplace }\end{array}$ & $\begin{array}{l}\text { 'What factors determine your } \\
\text { food choices?' } \\
\text { 'What facilitates your choosing } \\
\text { healthy food?' }\end{array}$ \\
\hline $\begin{array}{l}\text { Barriers to healthy eating } \\
\text { at workplace }\end{array}$ & $\begin{array}{l}\text { 'What prevents you from } \\
\text { choosing healthy food?' }\end{array}$ \\
\hline
\end{tabular}

used an iterative process by discussing each FGD immediately after completion and suggesting further detailed probing in emerging themes from the previous findings. For example, a theme on healthy alternatives to white rice emerged. In the subsequent FGDs, we added separate questions on healthy alternatives to white rice.

The team developed the focus group guidelines and reviewed for content and readability after pretesting with nine participants, all of whom were employees of the hospital. However, this pre-tested focus group was not included in this analysis. The FGD guide consisted of semi-structured open-ended questions guided by a socioecological model ${ }^{23}$ focusing on institutional and organisational factors. Probes for the questions were included to ensure consistency across groups and thorough understanding of the topics. The guide included topics on three main domains: (1) perceptions of healthy and unhealthy eating, (2) facilitators to healthy eating in the worksite and (3) barriers to healthy eating in the worksite. Examples of questions in each domain are presented in table 1.

\section{In-Depth interviews}

Investigators DT or AS conducted semi-structured in-depth interviews in Nepali with the cafeteria operators and administrative managers using a pretested interview guide in a private room of the hospital. The interviews aimed to understand the facilitators of and barriers to healthy eating from the cafeteria operators and managers' perspective. The moderator interviewed the participants employing open-ended questions to elicit their views on healthy and unhealthy eating, facilitators and barriers to healthy eating in the worksite, operational and managerial aspects of the cafeteria, and their views on the factors that facilitate and impede making changes that would promote healthier eating. The questions such as 'What are healthy and unhealthy foods in your cafeteria?', 'What changes are necessary for making cafeteria healthier?', 'What are factors that could facilitate making the cafeteria's food offerings healthier?' and 'What are the challenges for making cafeteria healthier?' were asked. In each case, the moderator probed to draw out further descriptive information.
An iterative process was used for data collection. After each interview, we discussed each interview and identified the topics to be deeply explored by the themes emerging in earlier interviews.

\section{Analysis}

All FGDs and interviews were transcribed verbatim into Nepali by trained research assistants. To ensure quality control, AS and DT independently reviewed the transcripts against the audio recording for potential discrepancies or incomplete data. A thematic analysis approach was used for data analysis. ${ }^{24}$ This process involved the investigators' familiarising themselves with the data, generating initial codes, searching for themes, reviewing themes, defining and naming themes, and producing the report. One FGD and two interview transcripts were coded inductively by two independent coders to enhance the validity of the data. The coders then compared the coding schemes and resolved any differences. The codebook was then finalised. All the transcripts were coded using R package for Qualitative Data Analysis (RQDA); segments of the text that related to a common theme were pieced together; emergent themes were identified, reviewed and defined.

\section{Patient and public involvement}

No patient and public were involved in the design, planning and conception of the study

\section{RESULTS}

\section{Characteristics of the participants}

Thirty-three adults participated in four FGDs that ranged from 7 to 10 participants per session. Nine canteen and hospital administration staffers participated in in-depth interviews. The characteristics of the participants are presented in table 2 . The mean age of participants was 33 years, range from 23 to 44 years. Sixty per cent were male. About half earned less than US\$3 per day. About $48 \%$ selfreported as alcohol drinkers and $10 \%$ as smokers. Fifty per cent of them were overweight, $6 \%$ reported having high blood pressure and 2\% reported having diabetes.

\section{Perceptions of healthy and unhealthy eating}

The participants explained the healthy and unhealthy food in terms of food groups, characteristics of food and cooking processes.

\section{Healthy eating}

Most of participants described healthy eating as hygienically prepared food and a balanced diet, defined as a mix of carbohydrates, proteins, fats, minerals and vitamins consumed according to one's level of physical activity. The support staff group however, who were less well educated than the other groups, were generally unaware of what a balanced diet means. Most of participants considered fruits and vegetables, and the traditional Nepali diet of white rice, lentil soup and vegetable curry to be healthy foods. Physicians, on the other hand, criticised this 
Table 2 Baseline characteristics of the participants

\begin{tabular}{|c|c|c|c|}
\hline Characteristics & Focus group participants $(n=33)$ & In-depth interviews participants $(n=9)$ & Total \\
\hline Age (mean $\pm S D)$ & $32.8 \pm 5.5$ & $35.3 \pm 9.9$ & $33.33 \pm 6.43$ \\
\hline Male, n (\%) & $17(51.5)$ & $8(88.9)$ & $25(59.5)$ \\
\hline$<\$ 3 /$ day & $14(42.4)$ & $6(66.7)$ & $20(47.6)$ \\
\hline$>\$ 3 /$ day & $19(67.6)$ & $3(33.3)$ & $22(52.4)$ \\
\hline High school and lower & $13(39.4)$ & $3(33.3)$ & $16(38.1)$ \\
\hline More than high school & $20(70.6)$ & $6(66.7)$ & $26(61.9)$ \\
\hline \multicolumn{4}{|l|}{ Alcohol drinking, n (\%) } \\
\hline Non-drinker & $18(54.5)$ & $4(44.4)$ & $22(52.4)$ \\
\hline Drinker & $15(45.5)$ & $5(55.6)$ & $20(47.6)$ \\
\hline Non-smoker & $26(78.8)$ & $6(66.7)$ & $32(76.2)$ \\
\hline \multicolumn{4}{|l|}{ Vegetarian, n (\%) } \\
\hline Yes & $2(6.1)$ & $0(0.0)$ & $2(4.7)$ \\
\hline No & $31(93.9)$ & $9(100.0)$ & $40(95.3)$ \\
\hline \multicolumn{4}{|l|}{ BMI categories, n (\%) } \\
\hline Normal $(18.5-<25) \mathrm{kg} / \mathrm{m}^{2}$ & $17(51.5)$ & $4(44.4)$ & $21(50.0)$ \\
\hline Overweight $(25+) \mathrm{kg} / \mathrm{m}^{2}$ & $16(49.5)$ & $5(55.6)$ & $21(50.0)$ \\
\hline \multicolumn{4}{|l|}{ Known hypertension, n (\%) } \\
\hline Yes & $2(6.1)$ & $4(44.4)$ & $6(14.3)$ \\
\hline
\end{tabular}

BMI, body mass index.

traditional Nepali diet as unhealthy due to its high carbohydrate content, particularly when accompanied by-as it often is-white rice and potatoes. Other items including meat, fish, whole grains, yoghurt and so on were also considered healthy by most participants. Most participants also equated the words 'healthy' and 'hygienic' and expressed the view that hygienically prepared foods in general are by definition healthy foods.

Thus, for example, a typical response by a health professional was:

Healthy food means that it contains all the necessary nutrients. On the top of that, it should also be in an appropriate amount according to the age and type of work of the consumer. Moreover, we understand that 'healthy' means 'hygienic', that is, free from harmful microorganisms.

Whereas a typical response from support staff participants was:
Healthy and balanced means rice, lentils, vegetables, fish and meat ... provided they clean and good (i.e. hygienically prepared).

Unhealthy eating

Unhealthy eating was defined by most participants as the consumption of stale (Basi) and unhygienic food. Most participants reported that oily foods or fast foods such as packaged instant noodles, chips and soda (Coke, Pepsi, Fanta or Sprite) were unhealthy. However, one support staff participant stated that the sodas were useful for treating gastritis:

My mother used to say that Coke is good for gastritis. She would ask me to bring 'that black drink' (Coca Cola).

Health professionals reported that excess consumption of carbohydrates such as rice was unhealthy. 
Food should be considered in both qualitative and quantitative way ... Healthy food means a balanced diet that contains adequate amounts of protein, carbohydrates, etc. Overeating [anything] is unhealthy. (A health professional).

Support staff, on the other hand, expressed no concern about the amount of rice consumed. Most participants said that fried food was unhealthy. Almost all participants, however, expressed concerns about the overuse of chemical fertiliser and insecticides in food.

When questioned about foods that are risky for diabetics or those prevent diabetes, the majority of participants cited as risky those foods containing high amounts of sugar and diets high in carbohydrates like white rice and potatoes, and fatty foods. Conversely, foods such as whole wheat flat bread (roti), fruits and vegetables, and parboiled rice were considered to be preventive of obesity and diabetes. Health professionals also mentioned that high fibre diets could help prevent diabetes.

Several misconceptions about diet and diabetes were expressed, for example:

- Washing white rice multiple times before cooking decreases the quantity of carbohydrates.

- Eating fruits and salads can increase the risk for diabetes.

- Eating irregularly can lead to diabetes.

- Satiation after eating causes weight gain.

- Eating Taichung rice (a short-grain rice variety largely used to make beaten rice) causes diabetes and obesity if served as boiled rice.

\section{Consumers' perspective on facilitators to healthy eating}

The most commonly reported factors that facilitate healthy eating were: (a) the availability of or the lack of healthy food options, (b) the promotion of healthy foods and healthy eating, (c) the stakeholders' (ie, the hospital administration) involvement and (d) the level of education of the employee/participant.

Table 3 presents a structured list of the respondents' perceptions of the facilitators and barriers to healthy cafeteria eating.
Availability of healthy food options: Most participants reported that unhealthy foods should be gradually replaced by healthier foods.

if we give an option for whole wheat roti, those who want rice will still eat rice. (A health professional)

\section{Promotion of healthy food and healthy eating}

Most participants said that healthy food should be presented in an appealing way and that healthy food options should be promoted by educating both providers and consumers.

There should be attractive posters visible in our canteen when we enter and leave to increase awareness so that we will avoid unhealthy food. (An administrative staffer)

\section{The involvement of influential stakeholders}

Most participants also emphasised that there should be active involvement of canteen management and hospital administrators in the process of change.

Rather than asking the canteen staff to change the cafeteria menu, changes should be implemented by more influential people in the administration. (A support staffer)

\section{Education level of employee}

Some participants expressed the idea that hospital is uniquely positioned to promote healthier eating since many employees are health professionals who are well aware of the health benefits and expected to be receptive of changes that improve food quality.

Most of us are well-educated doctors and medical professionals...I am not sure about other places, but in the hospital cafeteria, the consumers are concerned about their health. (A health professional)

\section{Providers' perspectives on facilitators to healthy eating}

The cafeteria manager pointed out that DH-KUH subsidises the cost of the food served in the four cafeterias which attempt to operate on a break even basis. All

Table 3 Themes and sub-themes identified through focus group discussions and in-depth interviews

\begin{tabular}{ll} 
Facilitators of healthy eating & Barriers to healthy eating \\
\hline $\begin{array}{l}\text { Consumers' perspectives: } \\
\text { Individual: education level of employee. }\end{array}$ & $\begin{array}{l}\text { Consumers' perspectives } \\
\text { Environmental: availability of healthy options; stakeholder's } \\
\text { involvement in promotion of healthy food and healthy }\end{array}$ \\
$\begin{array}{ll}\text { eating. } \\
\text { Providers' perspectives: }\end{array}$ \\
$\begin{array}{l}\text { Individual } \\
\text { human resources to prepare healthy foods. }\end{array}$ \\
$\begin{array}{l}\text { Environmental: stakeholder's involvement, income of } \\
\text { cafeteria, health education about healthy eating to cafeteria } \\
\text { staff. }\end{array}$ & $\begin{array}{l}\text { Providers' perspectives } \\
\text { healthy cooking. }\end{array}$ \\
\hline
\end{tabular}


participants noted their appreciation of the fact that the cost of food at the cafeterias is less than the regular market price.

The cafeteria operators expressed concern that the lack of knowledge among cafeteria staff about what constitutes a healthy diet and expressed the view that providing health education to the staff would facilitate the making of changes to their menu offerings.

If we get training on healthy eating, we will know more about the health effects of the food items we serve. (A cafeteria staffer)

One cafeteria operator said that 'higher level authorities' (ie, as hospital administrators and health professionals) should be involved in making any changes to the hospital cafeterias' offerings, including determining the menu and the prices, as healthier foods could cost more. Another cafeteria manager suggested forming a committee made up of cafeteria operators, administrative staff, medical doctors and nutritionists to decide on menu changes and revised pricing, and to monitor the availability of healthier options.

We keep talking about the changes in menu and price with 'the Sirs' (ie, the higher authorities) ... such decisions (on menu and price) should be taken by the system.

\section{Consumers' perspective on barriers to healthy eating}

The major barriers to healthy eating cited by consumers in the FGDs were: (a) the unavailability of healthy options, (b) the lack of human resources needed to prepare healthy foods, (c) the higher cost of healthy foods and (d) individual preferences for non-healthy foods.

\section{Unavailability of healthy options}

Many participants mentioned the lack of healthy food options in the cafeterias:

We are ready to start consuming healthier food, but the cafeteria should provide it. (A health professional)

\section{Inadequate human resources}

Many participants expressed the view that the cafeterias might lack the necessary human resources to prepare more healthy food options and suggested adding items like oats, fruits that require little additional labour or automated machines such as electric fruit juice or roti makers.

I think that there are inadequate human resources and that is why there are not better options. Everyone is always busy in there (the cafeteria). (A health professional).

\section{Higher cost of healthier foods}

Most participants in all groups mentioned the higher price of healthy food as a concern. The support staff group especially commented that consumers might not be eat fruits even if they are added to the menu because of their high price. In contrast, most health professionals indicated their willingness to pay more for healthier food.

We (support staff) consume less (fruit). But, higher level staff (doctors and nurses), consume more (fruits). After all, it is all about money. (A support staffer)

\section{Food preferences}

Most participants expressed the concern that changing food preferences would be difficult because most Nepali consumers prefer spicy and oily foods. In addition many also love such 'junk food' items as instant noodles, samosas, cream donuts and soft drinks.

You are talking about removing instant noodles? It is easy to say, but everyone prefers fast food such as instant noodles, samosas, donuts. Removing such food will lead to objections. (An administrative staffer)

\section{Providers' perspective on barriers to healthy eating}

The major barriers to healthy eating reported by the canteen operators were: (a) lack of adequate human resources, (b) lack of knowledge about healthier foods and the skills to prepare them and (c) the unavailability of healthier food in the local market.

\section{Inadequate human resources}

Canteen operators reported that they have insufficient staff to prepare such healthy foods such as whole wheat flat bread (roti), fruits and salads which they say are more labor-intensive. The human resource manager however thought that measures to increase the efficiency of the available kitchen staff would suffice to allow such changes.

Two people are needed and it takes hours to prepare whole wheat roti; and one more to serve it. We do not have enough staff. (A cafeteria staffer)

\section{Inadequate knowledge and skills of healthy eating and food} preparation

Most participants expressed the view that the cafeteria staffs lack adequate knowledge of healthy eating. They had occasionally received training on hygiene, but never on healthy foods or cooking.

Cafeteria staffs don't know which foods are healthy or unhealthy. Most people, even I don't know which is which. (A cafeteria manager)

\section{Unavailability of healthy foods in the local market}

Cafeteria operators and the manager reported that healthy foods such as brown rice, brown bread and organic vegetables were unavailable in the local market and their regular food suppliers could not supply such foods.

Unavailability is one of the barriers. Where can we get brown rice? (A cafeteria manager) 


\section{DISCUSSION}

Most consumers equated hygienic foods and healthy foods. Health professionals, however, also described a healthy diet as a balance of carbohydrates, proteins, fats, minerals and vitamins consumed according to the physical activity level of the person. The participants identified foods such as fruits, vegetables, meat, fish and dairy items like yoghurt as healthy and fast and fried foods as unhealthy. From the consumers' perspectives, the facilitators of healthy eating were the availability of healthy food options, the promotion of healthy food and healthy eating, stakeholder involvement and the education level of the support staff. The barriers identified were the unavailability of healthy options, inadequate human resources to prepare healthy foods, the higher price of healthy foods and individual habitual preferences for unhealthy foods.

From the providers' perspective, the major facilitators to healthier eating were identified as the involvement and support of higher authorities in making changes. Providers also suggested the formation of a committee with representatives from the cafeteria staff and management, the human resources department, nutritionists and consumers, to promote healthier eating and to effect changes in the cafeterias' food offerings. The major barriers identified by providers were: inadequate human resources, lack of healthy foods supply in the local market and lack of knowledge and skills among the cafeteria staff about healthy eating and food preparation.

Almost all participants equated hygienic foods as healthy foods, especially the support staffs that are of lower socio-economic status. This equating hygienic and healthy could be a result of the Nepal government's long standing and large scale health education campaigns against food-borne diseases such as diarrhoea, cholera and typhoid. ${ }^{25}$ Support staff for the most part did not express concerns about food quality or quantity. Similar findings were reported from a study among manual labourers in eastern Nepal. ${ }^{21}$ This highlights the need for more education among the general population that focuses healthy eating in terms of food quality and healthy quantities.

Most participants identified fruits and vegetables as healthy, which is incongruous with another study from Nepal. ${ }^{21}$ Despite the apparent knowledge, $99 \%$ of Nepalese consume less than five servings of fruits and vegetables per day. ${ }^{9}$ Unaffordability was reported as a major barrier to fruit consumption. In addition, the availability of fruits and vegetables is seasonal in Nepal, so, it can be difficult to ensure the regular supply of fruits and vegetables at an affordable price.

One of the major factors of healthy eating identified by participants in this study was the unavailability of affordable healthy food options in the cafeteria. This finding is consistent with other studies from Nepal in which employees reported the presence of healthy food options to be major motivator for healthy eating. ${ }^{21}$ Another qualitative study found that a lack of affordable, appetising, healthier food and drink choices at a worksite was major barrier to healthy eating. ${ }^{18}$ Yet another review of research on eating behaviours among nurses reported the unavailability of healthy options in an onsite cafeteria and in vending machines as a barrier to healthy eating. ${ }^{6}$

Another factor that emerged in the discussions was that the involvement and 'ownership' of all the stakeholders is necessary for making changes in the foods offered in the cafeterias. The administrative staff especially emphasised the need for the involvement of higher level authorities for making major decisions about changes. In addition, they recommended creating a committee representing all the stakeholders. Consultation with stakeholders and their 'buy in' was repeatedly cited as a key component for successful implementation of any programme. ${ }^{26} 27$

The canteen operators and manager also highlighted the unavailability of healthy foods in the local market as interfering with the regular supply to the hospital cafeterias. Other studies also show that the availability of healthy food at local market acts as an obstacle to consuming healthy food. ${ }^{28} 29$ Obviously, availability of healthy food in the stores has the potential to influence purchasing patterns and dietary intake. Both cafeteria users and managers emphasised the potential effect broader environmental level factors such as price, availability, access and the influence of the higher administration on healthy eating. These factors could potentially be addressed through a strong administrative commitment and policies to offer healthy foods at affordable prices. Policy changes have increasingly been recognised as essential components of worksite health promotion. ${ }^{30}$ Changes solely in the workplace environment may not be enough to make changes in healthy behaviour. ${ }^{31}$ Other social context factors such as social support and social norms also substantially affect the perceptions and behaviour of employees. Social norms have been studied as a way to promote nutrition. ${ }^{32}$

One of the major barriers to healthy eating is higher price of healthy foods. A study from Tanzania reported major barriers for consumption of healthy food as high price, scarcity and negative perceptions. ${ }^{33}$ Cox et al also identified the lack of affordable and acceptable food options as a barrier to healthy eating. ${ }^{34}$ Thus, while designing any intervention, the higher cost of healthy options should be addressed. The research has shown that subsidies for healthier foods significantly increase their purchase and consumption. ${ }^{35}$ Such a strategy, however, would be challenging in settings where cafeterias are profit-oriented. ${ }^{18}$ However, Sforzo et al found that despite removing barriers to healthy eating such as cost and inconvenience, other factors (such as time and motivation) could still prevent healthy eating at work. ${ }^{36}$ In our setting however, the price of the cafeteria food was determined by the worksite administration and profit-making was not a major motive. Therefore, although price is a major determinant of healthy eating in other settings, in this worksite it could be a positive point in any effort to bring about changes. 
Personal preferences for unhealthy foods were also commonly reported as a barrier to healthy eating. Another study has also reported that food characteristics including taste, appearance and smell strongly influence food choices. ${ }^{37}$ Taste perception, taste preference, food preference and food selection and consumption all influence each other. ${ }^{38}$

Lack of knowledge among cafeteria staff was also commonly cited as a major barrier to healthier eating. To respond to this, the administrative authorities have suggested staff training which has elsewhere been seen as essential. ${ }^{39}$ Another study from eastern Nepal also reported the need for cafeteria staff training on healthy diets and healthy meal preparation methods. ${ }^{21}$ Both consumers and cafeteria staff noted the lack of human resources to provide food options. However, the administrative authorities expressed the view that increasing staff efficiency and productivity might be more important than simply adding more staff and suggesting automating certain functions, such as roti-making and juicers.

A major limitation of this study is its exploration of facilitators and barriers in only a single worksite. Nor have we explored the broader environmental, contextual, social and commercial determinants of healthy eating beyond this worksite setting. This was intentional as the study was primarily conducted to understand healthy eating and its determinants in a specific worksite setting to develop worksite-specific interventions to promote healthy foods there. Further, we included a small number of people who may not be fully representative of the worksite. However, we conducted four stratified FGDs of different cadres of employees representing both high and low socio-economic status in the workplace. We did not create strata by body mass index although we recognise that overweight/obese individuals may have different perceptions of healthy eating and barriers or facilitators for eating than healthier individuals. Also, the surveyed worksite is a non-profit organisation with in-house subsidised cafeterias; thus, these findings may not be generalisable to a privately run tertiary hospital, or to worksites where the cafeteria is profit oriented. Social desirability bias may also have occurred if the focus group participants felt that they could not freely express their personal barriers or their knowledge of healthy eating.

Despite these limitations, we believe there are several notable strengths to this study. It is the first study to explore the facilitators and barriers to healthy eating in a hospital setting in Nepal. The study considered a wide range of staff to obtain their views. We have explored the views of cafeteria users as well as cafeteria operators. Among the cafeteria users, there were four strata of support staff, administrators and managers, and health professionals with and without shift duty. We have identified a complex picture of views and opinions about healthy eating in the workplace and the consequent enablers and challenges for designing an effective workplace intervention to promote healthy-eating.

The results of this study are valuable in designing appropriate cafeteria-based interventions to sustained healthy eating behaviours in worksites in Nepal. The availability of healthy food options at an affordable price, involvement of stakeholders at all levels of decision-making, and increasing awareness of healthy eating would be crucial parts of any worksite based environmental intervention to improve employees' diets. Interventions focusing on healthful, less expensive food preparation, or selection of more convenient yet still inexpensive and healthful foods, may help overcome the most common barriers identified in this population.

\section{CONCLUSIONS}

Among the employees of the hospital, healthy food was commonly defined as a hygienic and balanced diet. In addition, fruits and vegetables were considered healthy. The availability of affordable healthy foods in the cafeteria, along with increased health awareness, commitment from cafeteria managers, and a regular supply of healthy food from market can result in healthy food choice in the workplace. These factors need to be addressed in order to design cafeteria-based intervention to promote healthy eating in Nepal.

\section{Author affiliations}

${ }^{1}$ Department of Community Medicine, Kathmandu University School of Medical Sciences, Kathmandu, Nepal

${ }^{2}$ Department of Public Health, Kathmandu University School of Medical Sciences, Kathmandu, Nepal

${ }^{3}$ Department of Epidemiology, Harvard University T H Chan School of Public Health, Boston, Massachusetts, USA

${ }^{4}$ Family Health International 360, Kathmandu, Nepal

${ }^{5}$ Nutrition, Harvard School of Public Health, Boston, Massachusetts, USA

${ }^{6}$ Department of Nutrition, Harvard University T H Chan School of Public Health,

Boston, Massachusetts, USA

${ }^{7}$ Department of Biostatistics, Yale University School of Public Health, New Haven, Connecticut, USA

${ }^{8}$ Department of Biostatistics, Center on Methods for Implementation and Prevention Science, New Haven, Connecticut, USA

Acknowledgements We thank Ms. Dishya Sapkota, Dr. Prajjwal Pyakurel, Dr. Puspanjali Adhikari and Dr. Rajeev Shrestha for their inputs. We also thank all the participants of the study for providing their valuable time and expressing their views and opinions.

Contributors DT and AS conceived the study. AS, DT, VM, JM, BMK and DS contributed to the design of the study and development and pretesting of tools. AS and DT contributed to data collection and transcription. AS, DT and AR participated in management and analysis of the data. DT and AS developed the manuscript. All authors read and approved the final manuscript.

Funding This study was funded by NIH Director's Pioneer Award (award no: 5DP1ES02545903).

Competing interests None declared.

Patient consent for publication Not required.

Ethics approval We obtained ethical clearance from the Institutional Review Board of the Harvard School of Public Health and the Institutional review Committee of the Kathmandu University School of Medical Sciences. We took the written informed consent from each participant before participation in the study.

Provenance and peer review Not commissioned; externally peer reviewed.

Data availability statement № data are available. No additional data are available.

Open access This is an open access article distributed in accordance with the Creative Commons Attribution Non Commercial (CC BY-NC 4.0) license, which 
permits others to distribute, remix, adapt, build upon this work non-commercially, and license their derivative works on different terms, provided the original work is properly cited, appropriate credit is given, any changes made indicated, and the use is non-commercial. See: http://creativecommons.org/licenses/by-nc/4.0/.

\section{ORCID iD}

Archana Shrestha http://orcid.org/0000-0002-4741-090X

\section{REFERENCES}

1 National Research Council (US) Committee on Diet and Health. Diet and health: implications for reducing chronic disease risk. Washington, DC: National Academies Press (US), 1989.

2 Roberts CK, Barnard RJ. Effects of exercise and diet on chronic disease. J Appl Physiol 2005;98:3-30.

3 Eckel RH, Jakicic JM, Ard JD, et al. 2013 AHA/ACC guideline on lifestyle management to reduce cardiovascular risk: a report of the American College of Cardiology/American heart association Task force on practice guidelines. J Am Coll Cardiol 2014;63:2960-84.

4 George SM, Ballard-Barbash R, Manson JE, et al. Comparing indices of diet quality with chronic disease mortality risk in postmenopausal women in the women's health Initiative observational study: evidence to inform national dietary guidance. Am J Epidemiol 2014;180:616-25

5 Bissonnette-Maheux V, Provencher V, Lapointe A, et al. Exploring women's beliefs and perceptions about healthy eating blogs: a qualitative study. J Med Internet Res 2015;17:e87.

6 Nicholls R, Perry L, Duffield C, et al. Barriers and facilitators to healthy eating for nurses in the workplace: an integrative review. $J$ Adv Nurs 2017;73:1051-65.

7 Thomas EL, Puig Ribera A, Senye-Mir A, et al. Promoting healthy choices in workplace Cafeterias: a qualitative study. J Nutr Educ Behav 2016;48:138-45.

8 Nepal Health Research Council. Assessment of burden of disease in Nepal, 2009. Kathmandu, Nepal: Nepal Health Research Council, 2018.

9 Aryal KK, Mehata S, Neupane S, et al. The burden and determinants of non communicable diseases risk factors in Nepal: findings from a nationwide steps survey. PLoS One 2015;10:e0134834.

10 Shrestha A, Koju RP, Beresford SAA, et al. Food patterns measured by principal component analysis and obesity in the Nepalese adult. Heart Asia 2016;8:46-53.

11 Vaidya A, Pathak RP, Pandey MR. Prevalence of hypertension in Nepalese community triples in 25 years: a repeat cross-sectional study in rural Kathmandu. Indian Heart J 2012;64:128-31.

12 Shrestha A, Koirala B, Koju RP, et al. Dietary patterns, hypertension and diabetes in nepal-a community-based study. Int $J$ Health Nutrition 2016;7:20-8.

13 Quintiliani L, Poulsen S, Sorensen G. Healthy eating strategies in the workplace. Int J Workplace Health Manag 2010;3:182-96.

14 Engbers LH, van Poppel MNM, Chin A Paw MJM, et al. Worksite health promotion programs with environmental changes: a systematic review. Am J Prev Med 2005;29:61-70.

15 Dodson EA, Hipp JA, Gao M, et al. The impact of worksite supports for healthy eating on dietary behaviors. J Occup Environ Med 2016;58:e287-93.

16 Anderson LM, Quinn TA, Glanz K, et al. The effectiveness of worksite nutrition and physical activity interventions for controlling employee overweight and obesity: a systematic review. Am J Prev Med 2009;37:340-57.

17 Mache S, Jensen S, Jahn R, et al. Worksite health program promoting changes in eating behavior and health attitudes. Health Promot Pract 2015;16:826-36.
18 Pridgeon A, Whitehead K. A qualitative study to investigate the drivers and barriers to healthy eating in two public sector workplaces. J Hum Nutr Diet 2013;26:85-95.

19 Devine CM, Nelson JA, Chin N, et al. "Pizza is cheaper than salad": assessing workers' views for an environmental food intervention. Obesity 2007;15 Suppl 1:57S-68.

20 Faugier J, Lancaster J, Pickles D, et al. Barriers to healthy eating in the nursing profession: Part 1. Nurs Stand 2001;15:33-6.

21 Shrestha A, Pyakurel P, Shrestha A, et al. Facilitators and barriers to healthy eating in a worksite cafeteria: a qualitative study from Nepal. Heart Asia 2017;9:e010956.

22 Swift JA, Tischler V. Qualitative research in nutrition and dietetics: getting started. J Hum Nutr Diet 2010;23:559-66.

23 Townsend N, Foster C. Developing and applying a socio-ecological model to the promotion of healthy eating in the school. Public Health Nutr 2013;16:1101-8.

24 Braun V, Clarke V. Using thematic analysis in psychology. Qual Res Psychol 2006;3:77-101.

25 DOHS. Annual Report 2072/73. In: Department of health services, Ministry of health and population, eds. Kathmandu Nepal, 2017.

26 Fitzgerald S, Geaney F, Kelly C, et al. Barriers to and facilitators of implementing complex workplace dietary interventions: process evaluation results of a cluster controlled trial. BMC Health Serv Res 2016;16:139.

27 Burke K, Morris K, McGarrigle L, et al. An introductory guide to implementation: terms, concepts and frameworks, 2012.

28 Pollard J, Kirk SFL, Cade JE. Factors affecting food choice in relation to fruit and vegetable intake: a review. Nutr Res Rev 2002;15:373-87.

29 Krukowski RA, West DS, Harvey-Berino J, et al. Neighborhood impact on healthy food availability and pricing in food stores. $J$ Community Health 2010;35:315-20.

30 Kahn-Marshall JL, Gallant MP. Making healthy behaviors the easy choice for employees: a review of the literature on environmental and policy changes in worksite health promotion. Health Educ Behav 2012;39:752-76.

31 Gorman E, Ashe MC, Dunstan DW, et al. Does an 'activitypermissive' workplace change office workers' sitting and activity time? PLoS One 2013;8:e76723.

32 Ball K, Jeffery RW, Abbott G, et al. Is healthy behavior contagious: associations of social norms with physical activity and healthy eating. Int J Behav Nutr Phys Act 2010;7:86.

33 Muhihi AJ, Shemaghembe E, Njelekela MA, et al. Perceptions, facilitators, and barriers to consumption of whole grain staple foods among overweight and obese Tanzanian adults: a focus group study. ISRN Public Health 2012;2012:1-7.

34 Cox DN, Anderson AS, Reynolds J, et al. Take five, a nutrition education intervention to increase fruit and vegetable intakes: impact on consumer choice and nutrient intakes. Br J Nutr 1998;80:123-31.

35 An R. Effectiveness of subsidies in promoting healthy food purchases and consumption: a review of field experiments. Public Health Nutr 2013;16:1215-28.

36 Sforzo GA, Kaye MP, Calleri D, et al. Free choice access to multipoint wellness education and related services positively impacts employee wellness: a randomized and controlled trial. J Occup Environ Med 2012;54:471-7.

37 Glanz K, Basil M, Maibach E, et al. Why Americans eat what they do: taste, nutrition, cost, convenience, and weight control concerns as influences on food consumption. J Am Diet Assoc 1998;98:1118-26.

38 Drewnowski A. Taste preferences and food intake. Annu Rev Nutr 1997;17:237-53.

39 Holdsworth M, Haslam C. A review of point-of-choice nutrition labelling schemes in the workplace, public eating places and universities. J Hum Nutr Diet 1998;11:423-45. 